\title{
ESPELHOS QUE CONGELAM A IMAGEM
}

\section{RESUMO}

Através de testemunhos directos que a memória pessoal e a recorrência preservaram, o autor observa os contornos particulares da fotografia colonial da pessoa de um fotógrafo de Angola - 1940-1976, Francisco Júnior "Quitos" e a sua existência na cidade de Lobito. São igualmente ensaiadas inferências técnicas e teóricas a partir de quadros conceptuais conhecidos e que têm ligado a Antropologia e a Sociologia do Visual à Fotografia.

\section{PALAVRAS-CHAVE}

Papel social da Fotografia; Fotógrafo; EspeIho; Desmaterialização da Fotografia;Arquivos.

\author{
Eduardo Jorge Esperança
}

\begin{abstract}
Through direct testimony, the personal memory and the recurrence of other memories preserved, the author notes the particular contours of colonial photography in a photographer of Angola-1940-1976, Francisco júnior "Quitos" and his life in the city of Lobito. Technical and theoretical inferences over most known conceptual frameworks are also tested in the way those have connected Visual Anthropology and Sociology to photography.
\end{abstract}

\section{KEYWORDS}

Social role of photography; Photographer; Mirror; Dematerialization of photography; Archives. 
Cumpre, portanto, uma função de integração, através do reforço ao sentimento de unidade familiar que se dá mediante a solenização e eternização de seus grandes momentos registrados na fotografia. Neste "rito do culto doméstico", a família faz-se ao mesmo tempo sujeito e objeto, na qual a inexistência da prática fotográfica pode significar omissão ou ato de dissolução. Partindo de Durkheim, que defende que a festa possui por função revivificar e recriar o grupo, Bourdieu compreende que a fotografia é o meio da solenização de seus momentos culminantes e da reafirmação da unidade. A fotografia, além de ser uma técnica de solenização, é uma técnica da festa; técnica de solenização da festa.

(MIRANDA, 2005, p. 47)

O cenário abrangente é uma cidade da Angola colonial, de cerca de 100 mil habitantes e existência recente - que nos anos 60 do século $X X$ perfaz 50 anos de idade, é movimentada e comercial, o segundo maior porto de mar de África e, nos dias de sol, um pequeno Hawai no grande continente, e a que a publicidade colonial chama a "sala de visitas de Angola": Lobito, $500 \mathrm{~km}$ a sul de Luanda ao longo da costa. Existe na cidade uma muito pequena alta burguesia proprietária ou administradora de empresas de médio porte, mas que não passa da "meia dúzia" e que na sua maioria vive na Restinga, a parte mais turística e bem cuidada da cidade, igualmente ocupada por uma média burguesia um pouco maior e com expectativas de ascender socialmente; uma pequena burguesia bem mais vasta e ocupando praticamente todo o resto da cidade não periférica e, finalmente, toda a restante população de rendimentos baixos, habitando os bairros ultra-periféricos com menores condições de salubridade e mais longe do centro. O Lobito é o porto e ponto de partida do Caminho de Ferro de Benguela que atravessa Angola até ao Congo e depois até à contra-costa em Moçambique - linha ferroviária que serve todo o centro de Angola, levando a partir do porto do Lobito todo o tipo de mercadorias de abastecimento para o território e migrnates Belgas e outros para o interior do Congo e Zambia; trazendo de lá minérios e viajantes para acesso à Europa e outros pontos do Globo.

O personagem activo é o fotógrafo mais conhecido na cidade - Francisco Júnior "Quitos». Antes de entrarmos adentro do papel social da fotografia, convido o leitor a observar duas fotos em forma de texto:

I.Um curto extracto biográfico extraído de «I 975 na Primeira Pessoa - Lobito, uma cidade com estórias por contar», Manuela Amoedo, ed. Nova Vega, Lisboa, 2016; e

2. Catorze comentários à biografia "postada" no Facebook, numa das páginas mais concorridas e dedicada à cidade do Lobito ${ }^{2}$, extraídos pelo autor de um total de 68 comentários, cerca de 6 meses após o falecimento de Quitos.

I. «Francisco Jorge Esperança Júnior nasceu em Luanda, a 6 de Setembro de 1926, filho de Aurora Alfredo e de Francisco Jorge Esperança. A sua primeira 
infância decorre em Calomboloca, próximo de Catete, onde o pai tem uma mercearia que abastece a população local.Aos 5 anos, o pai Francisco Esperança leva-o e ao irmão José para Portugal, onde ficam a fazer a instrução primária alojados, cada um, junto de uma família portuguesa amiga do pai, próximo da região de Tomar. Francisco Júnior não gosta que o confundam com Francisco Esperança (pai), nem que the chamem "chico" porque, argumenta, em Angola, "chico" é macaco. Então sugere que Ihe chamem "Quito" (de Francisquito). Como qualquer criança nessa idade ainda não domina completamente a língua e "arrasta" a última sílaba das palavras, fazendo-as parecer um "plural". Como o pai, é muito sociável e comunicativo, e as pessoas começam a chamar-lhe “Quitos”(...)Entretanto Quitos tem 10 anos, a família cresceu, e Francisco Esperança decide que Calomboloca não é o melhor sítio para a família Esperança prosperar e parte para o Lobito em busca de novas oportunidades. No Lobito consegue sub-alugar parte de um edifício, ao lado do Cinema Império, onde depois se localizaram os armazéns “Gomes \& Irmão”. O Hotel Império torna-se a fonte de subsistência da família Esperança no Lobito.A adolescência de Quitos é passada no Hotel Império onde a familia coabita com os hóspedes, numa cidade em crescimento, entre o porto e a estação do caminho de ferro. Quitos faz amizade com um "hóspede-de-longa-duração" amador de fotografia, que consegue montar uma pequena câmara escura num dos quartos. É o pai da $\mathrm{Dr}^{\mathrm{a}}$ Ofélia que ensina ao jovem os rudimentos da fotografia e o encoraja a construir ele próprio uma máquina fotográfica. Estamos no início dos anos 40 e, rapidamente, Quitos tenta conciliar as tarefas hoteleiras com a fotografia amadora, que ele começa por exercitar com os hóspedes e depois, por toda a cidade.(...)A cidade cresce rapidamente e o negócio da fotografia prospera. Quitos muda-se mais para o centro da cidade, junto do mercado e, pouco depois, transfere a loja para a Rua 15 de Agosto, um imóvel do Eng $^{\circ}$ Falcão, mais amplo que o anterior, e onde Quitos pode expandir as actividades além da fotografia, para o cinema, a reprografia, etc. Em 1964 vai aos laboratórios da AGFA em Colónia fazer um curso de vários meses para a produção de fotografia a cores. É inovador no país com um dos primeiros laboratórios de fotografia a cor. $\bigcirc$ negócio continua a crescer como o Lobito e Angola. Nos finais de 1974 ocorrem os primeiros conflitos armados urbanos. 1975 é o ano da quase total paralisia do país e da cidade devido aos conflitos armados. Quitos não quer sair de Angola por razão nenhuma mas, por segurança, em Setembro de 1975 faz embarcar a família para Portugal e fica sozinho no Lobito.Assiste à independência de Angola em 1976 e fotografa quem lá está. Quitos teima em ficar, mas um episódio recambolesco, característico destas situações em que os partidos em conflito tentam marcar pontos com a imagem de personagens populares como ele o era, para salvar a pele, obriga-o a arrumar uma mochila e pedir boleia ao primeiro que passasse rumo à Namibia. (...)Chega a Lisboa ainda sem a noção completa do que se está a passar. Tem esperança de poder voltar a Angola, mas esta vai-se rapidamente desvanecendo com o evoluir da situação de Guerra. (...)Lisboa não é o Lobito onde tantos anos de trabalho e construção de uma imagem própria haviam sido desfeitos de um dia para o outro. $O$ ânimo de Quitos e a alegria não mais foram os mesmos. Era um homem de meia-idade e, se ainda tinha força, tinha igual receio de se aventurar na reconstrução do que havia perdido. As novas tecnologias traziam a fotografia agora para outros patamares. Tudo passava pelo 
computador e máquinas digitais, mas o Quitos, já com setenta anos, não tinha vontade de se adaptar. Ficou por ali, fotografando e reencontrando amigos até o sustento da casa de fotografia começar a ser deficitário e ser obrigado a fechá-la e ir para casa. Orgulhava-se de ter chegado a fotografar quatro gerações dentro da mesma família; pais, filhos, netos e bisnetos. Contava que, antes de fechar a fotografia, Ihe tinham lá aparecido quatro moços de Luanda, que ele não conhecia, mas que o queriam conhecer a ele. Eram repórteres fotográficos dos jornais de Luanda e queriam saber quem era aquele «Quitos» que aparecia colado a todas as fotografias que estavam nos arquivos a que eles recorriam sempre que era necessário uma imagem mais antiga. Emocionou-se, como sempre, mas pouco tinha para lhes dizer ou dar.(...) $\bigcirc$ arquivo do seu trabalho tinha desaparecido, mas a internet devolvia-lhe agora muitas imagens que ele reconhecia muito bem, mesmo quando não tinham lá o seu nome. $O$ stress para a manutenção da casa de fotografia foi-lhe fatal.Adoeceu ainda a trabalhar e não mais recuperou. Morreu completamente lúcido, a chamar pela esposa, que o assistiu até aos últimos dias.»

2.J.F -Quitos é uma "personagem" que se mistura com a história do Lobito.As fotografias antigas da minha infância, dos meus pais e de todas as pessoas que me lembro têm todas aquea insígnia Quitos. Obrigado pela estória partilhada. J.M.A -Como apreciei o texto de um resumo da vida do Quitos. Acompanhei parte do seu percurso no Lobito. Sou um pouco mais novo, mas tive a felicidade de o conhecer e de admirar o seu profissionalismo e acima de tudo uma grande simpatia. (...) O sr. Quitos era um homem admirado e muito estimado por toda a população do Lobito.

A.L.V.-Tive de partilhar pois passei tantos anos a conviver com "QUITOS" e só agora conheci a sua história. Nunca é tarde para conhecer as grandes figuras da terra que ficou para sempre nos nossos corações.

H.F- Conheci o Quitos na sua loja perto da Almirante Reis, pois o meu pai disse-me onde ele trabalhava depois de ter vindo de Angola.Ainda revelei alguns rolos fotográficos nesta casa. (...) Sempre ouvi falar de Quitos e do seu grande talento. Parabéns pela história tão esclarecedora.

L.S. - Um grande obreiro e lutador incansável!... Conheci-o nos meus tempos de infância e juventude. Um verdadeiro gentleman. Fica a saudade do nosso sempre querido Quitos.

J.F.M.-Também o conheci, tirando-me fotografias. Quem não conheceu, ou ouvia falar nessa pessoa tão simpática?

F.C.- As minhas melhores fotos da juventude foram tiradas pelo Sr.Quitos, a quem naturalmente chamávamos apenas Quitos, o meu casamento também foi fotografado por ele, era um Senhor.

P.N.- Todos esses detalhes eram desconhecidos por mim e tantos outros. $O$ nome, o hotel Império...

Há pequenas coisas que podem mudar uma vida e até mudar o curso da história. Neste caso, aquele amador de fotografia que passou pelo Hotel Império, mudou literalmente o curso da história da cidade do Lobito, graças à fidelidade e dedicação do Quitos.

A.G.M.-Conheci-o pessoalmente,.. Nunca pensei que tivesse um passado tão repleto de curiosidades, assim como mesmo já mais tarde parece ter sido atraí- 
do para inúmeras aventuras .. Obrigado pela partilha ...Todas as razões para ter orgulho no velho Quitos.

A.M.-Apesar de conhecer a família e a sua história, ao ler este teu texto, fiquei muito emocionada.

O.N.I.M -Uma historia digna de uma realizacao cinematografica, de alto nivel e com fotografia do nosso QUITOS, um LOBITANGA inesquecível nos nossos corações.

M.C.- Nenhum lobitense desconhecia este senhor. Foi um popular cidadão do nosso Lobito.

J.F.- Realmente a familia Quitos é uma preciosidade, conhecida e.....querida de todos. Saudades e .mais não digo.......

G.S.- Quitos contribuiu para a Historia de todos nós. Fotos de casamento, baptizado, festas, e depois até filmes a cores como o do casamento de meus pais. Ele faz parte da historia de todos nós Lobitangas. Nunca o esqueceremos.

C.M. - E lembram-se quando o Quitos se punha a abanar as orelhas para nos fazer rir????????? Nunca vi ninguém fazer o que ele fazia KKKKKKKKKKK! J.G.- Bela história a história do Sr Quitos. Quando ele se instalou na Almirante Reis, o meu pai, que trabalhava na RDP por vezes passava por lá para dois dedos de conversa. Grande Quitos, inesquecível!

P.P.M. - Uma figura inesquecível.

F.V. -Obrigada pela partilha da história de vida deste senhor que é parte integrante das nossas vidas e da nossa cidade.

M.B.- Até me estou arrepiar ao ler toda esta historia pois bem o conheçi pois também morei no Lobito e tenho muitas fotografias tiradas por ele; estou muito triste ao saber que ele ja faleceu - levou ANGOLA com ele.

\section{O Fotógrafo e a Cidade}

O que descrevo decorre desde os finais dos anos 30 do séc. $X X$, altura em que Quitos inicia a sua actividade como fotógrafo, e o ano de 1976, ano da independência de Angola, fim do período colonial e início de uma guerra civil que duraria até 2002 e custaria, entre outros, cerca de dois milhões de mortos. A preponderância de Quitos neste testemunho reflexivo, deve-se à dimensão da sua empresa de fotografia e actividades periféricas, assim como à qualidade e quantidade de informação que sobre ele posso disponibilizar. Quitos é um "workaholic" que coloca a fotografia acima de tudo e, nos anos 60 há quem brinque com ele por essa altura insinuando que ele até dorme com a Rolleyflex ao pescoço. Quitos tem um portfolio invejável e faz fotografia de eventos sociais que é posteriormente exposta na ampla montra do seu estabelecimento no centro da cidade; casamentos, baptizados, comunhões, aniversários, eventos de empresas; faz fotografia comercial para publicidade, fotografia técnica para projectos de engenharia, fotografia aérea, fotojornalismo e cinema amador. Em todas as fotos, tal como Octávio coloca o timbre do seu nome na foto e esse seu signo aparece quando os possuidores das fotos as expõem pessoalmente ou nos jornais e revistas e, mais recentemente, quando começam a ser colocadas na Web por quem ele fotografou e nos arquivos de fotos das ex-colónias, reconhecidas e indexadas a partir do timbre no canto inferior direito da foto. Mas o trabalho que aqui mais nos interessa é esse de "fotografar pessoas a pedi- 
do delas" - de algum modo, o trabalho da fotografia enquanto espelho social ou, como the chama Umberto Eco - "Espelhos que congelam a imagem" (2016, p. 38). O impacto do trabalho do fotógrafo no imaginário das pessoas vai além da sua função enquanto manipulador de espelhos que congelam a imagem porque, enquanto animador de eventos, gestor de protocolos e auxiliar de produção de eventos, ele está presente no "fazer" e legitimação de todo esse imaginário, e acontece uma verdadeira semiose no espaço da foto, com a simples evocação do timbre - (Quitos) - que faz explodir, a par da evocação das fotos e eventos, todo o quadro mnésico das mais variadas situações geradoras de fotos. $E$ tudo isto ocorre no campo imaginário da memória. Mesmo hoje, com a foto instantânea desmaterializada, por pouco tempo que passe, o tempo de formação da imagem na consciência ocorre já no tempo da memória; imagine-se no tempo em que entre o evento e a exposição das fotos do mesmo poderiam demorar dias.

\begin{abstract}
O espelho é um fenómeno limiar, que marca os limites entre imaginário e simbólico. Entre os seis e os oito meses a criança confronta-se com a própria imagem reflectida no espelho. (...) mais tarde, o "momento em que se perfila a passagem do eu especular ao eu social (...) momento particular, único e irrepetível da ontogénese do sujeito. (...) o que é que torna uma fotografia numa imagem especular? Uma ideia pragmática segundo a qual a câmara escura deveria dizer a verdade tal como o espelho e, em qualquer dos casos, atestar a presença de um objecto impressor.(...) o que isto faz é que na ontogénese do sujeito o "estádio da fotografia» se situe muito mais tarde que o estádio do espelho. (ECO, 2016, pp. $16,17,39)$
\end{abstract}

\title{
O "comum" dos olhares
}

Encontro alguma resistência em separar especificidades e perfis específicos nos olhares pré e pós coloniais, neste caso, a partir de 1976. Isto pode ser contestado em outros espaços, mas em Angola, no fio do tempo, anos 40 até 1976, versus 1976 até séc. XXI, o que varia é a interposição da guerra civil entre a objectiva do fotógrafo (às vezes interdita) e os eventos sucedidos. Quanto ao tipo de eventos e olhares pré e pós coloniais - pelo menos nestas próximidades, os arquivos que percorro mostram-me apenas as ocorrências significativas tanto para os fotógrafos como para os objectos/sujeitos das suas fotos - os que as requisitaram e pouca alteração registo tanto nos olhares como nos enquadramentos que previlegiam as pessoas.

Existem características no fotógrafo de eventos que se mantêm até hoje. As principais incluem uma grande capacidade de entrosamento social. O fotógrafo deve ser capaz de, além de tirar fotografias, operar como animador do evento . Esta capacidade pode variar de fotógrafo para fotógrafo mas era bastante apreciada como uma mais valia profissional do fotógrafo, oferecendo um cunho específico ao evento "animado" por determinado fotógrafo. Além dessa capacidade de animação e simpatia geral, as capacidades ligadas propriamente à arte eram igualmente valorizadas mas com menos ênfase; o que as pessoas queriam era "ver se tinham ficado bem na fotografia"3 .

3 Será interessante pensar aqui a décalage cronica entre o momento do disparo e o da 
No mundo da fotografia argentífera, o momento da revelação só para o operador corresponde verdadeiramente a uma revelação - o momento em que a solução química devolve ao papel sensibilizado no ampliador a imagem impressa a luz no negativo exposto, e esta começa lentamente a aparecer no papel branco.A revelação que interessa ao sujeito fotografado é aquela que the aparece no álbum que lhe é entregue pelo fotógrafo com o conjunto das fotos do evento ou, comum neste período, a sua exposição na montra do estabelecimento do fotógrafo. Esta exposição, hoje equivalente à montra das fotos no site online, no Flickr ou no Facebook corresponde a um momento social de exposição-recepção não negligenciável. É, ao mesmo tempo, o momento de percepção do evento a duas dimensões, mas com narrativa imagética e "confronto" amigável com os pares e o trabalho do fotógrafo. É aqui igualmente perceptível a responsabilidade social do fotógrafo que, à semelhança do jornalista, ao mesmo tempo revela e expõe o evento, os envolvidos, o espaço e a narrativa do acontecido. É também o primeiro a colocar "likes" na foto, em particular no momento da entrega das fotos ao cliente, destacando o que ficou bem.

Estas capacidades sociais de animação que não são de nascença, desenvolvem-se no trabalho e solicitam o mais diverso tipo de sensibilidades - o humor não agressivo, a brincadeira não parva, a boa disposição não gratuita. Isto implica estar bem informado acerca do que se passa na cidade, ter bastantes conhecimentos pessoais e cruzamento de relações em todos os estratos sociais. Esta capacidade não era comum a todos os fotógrafos e, os mais solicitados e de maior sucesso eram os que, obviamente, melhor desempenho demonstravam nesta capacidade, embora isto não garantisse a amplitude do seu leque de clientes.

\section{Olhares e intenções e técnicas}

A generalidade dos eventos em que os fotógrafos participam têm um modo de organização e protocolos de enquadramento específicos. Quando o fotógrafo organiza as pessoas para serem fotografadas, coloca-as em grupos, maiores e menores - família, amigos, conhecidos, o padre, a cerimónia, - a reportagem civil possível. Se pensarmos em formas alternativas de fotografar, mesmo nos dias de hoje, pouco resta; são aquelas pessoas, aquele bairro, aquela igreja. Pode sempre ensaiar-se uma reportagem do tipo fotojornalistico, mas na maior parte dos casos não é o que o cliente solicitou.

O quadro de elucidação estrutural que nos alerta para a direcção do olhar (do fotógrafo) e a configuração dos objectos fotografados, faz sentido num universo bem mais vasto de uma infinitude de possibilidades na qual a selecção produz sentido. Neste quadro de fotografia colonial de eventos, o sentido maior é social e informativo, só depois documental, e na resposta a questões muito comuns; onde acontecia? Como se mostravam? O que destacavam? Quem convidavam? Como íam vestidos?

Quando destaco o que há aqui de comum, destaco o facto de o modus operandi do fotógrafo colonial dos anos 30 do séc. $X X$ em Angola - no início da colonização efectiva de Angola - não encontrar grandes diferenças de proto-

revelação/vizualização na fotografia argentífera, por comparação com a revelação imediata da imagem no espelho e, hoje na fotografia digital. 
colo na selecção e enquadramento de objectos entre essa data e a de hoje em Angola ou Portugal.

Do ponto de vista técnico, a diferença significativa, caso esse universo de alternativas seja alargado, reside no facto de hoje a camara digital permitir fotografar e filmar com a mesma facilidade e disponibilizar sem mais custos a possibilidade de um numero muito maior de "takes" e fotos. Em 1940 o negativo standard era o $6 \times 6$ ou o $120 \mathrm{~mm}$ que pouco mais oferecia que 9 ou 12 fotos por rolo fotográfico - era preciso mudar de rolo e a quantidade de fotos encarecia sobremaneira a reportagem. Nos anos 60 , o $35 \mathrm{~mm}$ já oferecia a possibilidade de rolos de 36 fotos, facilitando a quantidade mas não o custo que se mantinha ascendente a par da quantidade.

Eixo central aqui, do ponto de vista do fotógrafo no acto de fotografar e sem excessos de configuração era garantir que o cliente (fotografado) ficava satisfeito com a reportagem e, a seguir, que a sua imagem ou a imagem da sua cerimónia expostas na montra do estabelecimento fotográfico, não "envergonhassem nem o fotógrafo nem o fotografado. Mesmo não sendo pública a cerimónia, a exposição das fotos na montra do fotógrafo, depois do cliente as ter visto e autorizado a exposição, era esse sim o acto público e passível de juízo social a partir do contacto visual com as fotos.

Quando me ocorre a comparação com o Facebook em acesso permanente, aqui sim, há diferenças; com excepção dos que, na cidade têm por rotina de deslocação passar a pé frente à montra do fotógrafo, a generalidade do resto da comunidade só no fim de semana, por ocasião do passeio em familia se desloca pelas montras do centro da cidade e, entre olhares consumistas e outros juízos - por exemplo ao cruzar-se com outras familias - o olhar e comentar a montra do fotógrafo fazia parte dessa rotina de "likes" de fim-de-semana.

\section{Arquivos frágeis}

De algum modo, o disco rígido ou as memórias electrónicamente activas em que hoje se alojam os arquivos online, são a melhor garantia de sobrevivência de imagens pelo fenómeno da replicação em vários servidores de acesso a nível global. Aquilo que já existe há duas décadas e que, apenas por variação de acesso resolveram recentemente chamar "cloud", é um dos dispositivos para essa sobrevivência do arquivo. Precisamente por isto, a urgência da digitalização de imagens em suporte mais frágil e ainda a possibilidade de revivescência de imagens degradadas no papel e/ou negativo e restauradas com acesso a software apropriado.

Mais que uma função, o papel social da fotografia sobre o qual tanto se discorre, assume, para não irmos além de Lacan e U. Eco, um papel formativo ou “ontogénico". O fazedor de espelhos que congelam a imagem é igualmente o animador dos eventos em que se participa mais ou menos, o potencial amigo. Para lá de fazer imagens, ele faz espelhos que congelam a nossa imagem; ele participa na nossa "produção" seja ela de identidade, contexto imaginário ou mesmo existência possível fora da realidade-de-todos-os-dias. O fotógrafo é o fabricante do nosso álbum de registos e parte da nossa identidade social. Num espaço colonial onde a relação com a imagem passa, nesta época, apenas pela 
fotografia e o cinema ${ }^{4}$, com funções diferentes que atravessam ambas o imaginário dos circunstantes, a fotografia adquire, por ter espaço para isso, alguma capacidade mobilizadora desse imaginário.

\section{REFERÊNCIAS}

AMOEDO, M. «I 975 na Primeira Pessoa - Lobito, uma cidade com estórias por contar». ed. Nova Vega: Lisboa, 2016.

BARTHES, R. Câmara Clara. Edições 70 , Lisboa, 2012.

BECKER, H. S. "Photography and Sociology." In: Studies in the Anthropology of Visual Communication I. 3-26, 1974.

BOURDIEU, P. et alii, Un art moyen. Essai sur les usages sociaux de la photographie.

Éd. de Minuit, Le sens commun, 1965. Revue, 1970.

HARPER, D. «The image in sociology : histories and issues », Journal des Anthropologues. 80-8I | 2000, pp. |43-160. https://jda.revues.org/3 |82?lang=en

DUBOIS P. L’acte photographique. Paris : Éditions Labor, 1988.

ECO, Umberto. Sobre os espelhos e outros ensaios. Relógio D’água, Lisboa, 2016.

FACCIOLI, Patrizia. « La sociologie dans la société de l'image. » In : Sociétés. I/2007, n. 95, pp. 9-I8.

GOMBRICH E. "The visual image: its place in communication”, In: WODFIELD, R.The Essential Gombrich: Selected Writings on Art and Culture, Londres: Phaidon, 1996.

JONAS, Irène. "L'interprétation des photographies de famille par la famille » In :Sociologie de l'Art, I/2009 (OPuS 14), pp. 53-70.

http://www.cairn.info/revue-sociologie-de-l-art-2009-I-page-53.htm

MIRANDA, L. Pierre Bourdieu e o campo da Comunicação - por uma teoria da Comunicação Praxeológica. Porto Alegre: EdiPUC-RS, 2005.

SONTAG, S. Sur la photographie. Paris : Union Générale d’Éditions, coll. « 10/18 », 1983.

4 A pintura e a banda desenhada são aqui marginais e acedidas por um público muito selecto, e não existe televisão. 